\title{
Prevention of Esophageal Cancer: Experience of an Educational Campaign for Reducing Hot Tea Consumption in Iran
}

\author{
Farahnaz Mirzaei ${ }^{1}$, Tahereh Dehdari ${ }^{1 *}$, Amal Saki Malehi ${ }^{2}$
}

\begin{abstract}
Background: Given the association between drinking hot tea and the risk of esophageal squamous cell carcinoma, this study was designed to determine the effectiveness of an educational campaign based on the Theory of Planned Behavior (TPB) in reducing hot tea consumption among a sample of Iranian female students. Materials and Methods: In this quasi-experimental study, 130 primary-school female students in Salas Babajani, Kermanshah, Iran were randomly selected. A two-month campaign based on TPB constructs was developed and conducted for the intervention group. Combined mass media approaches (such as posters, pamphlet, and brochure) with small group and individual activities were used to transfer the campaign messages. Also, five 40-minute instructional sessions for the students and one session for their parents and teachers were held. The hot tea consumption, attitude, subjective norms, perceived behavioral control and no intention to drink hot tea were variables which were measured at baseline and again after 4 weeks. Results: There was a significant improvement in the perceived behavioral control and intention to drink no hot tea variables in the intervention group as compared to the control group following the campaign. In addition, significant reductions were found for the hot tea consumption and favorable attitude toward drinking hot tea in the intervention group as compared to the control group. Conclusions: Conducting educational campaigns based on TPB variables may reduce hot tea consumption among Iranian students.
\end{abstract}

Keywords: Campaign - hot tea consumption - esophageal cancer - student - theory of planned behavior - Iran

Asian Pac J Cancer Prev, 17 (1), 305-310

\section{Introduction}

Iran is one of the highest consumers of tea, especially black tea, in the world (Salahinejad and Aflaki, 2010). Despite the positive effect of tea on health (Gardner et al., 2007), if it is drunk at high temperature (up to $65^{\circ} \mathrm{C}$ ), it can damage the esophageal epithelia and consequently results in the increased risk of esophageal cancer in humans (Yuan et al., 2011). Drinking hot tea is a common harmful habit in Iran that starts at an early age, and regularly continues for life (Islami et al., 2007). The association between hot or very hot beverages consumption and the risk of esophageal cancer has been shown in published epidemiological studies from various countries (Onuk et al., 2002; Yuan et al., 2011) as well as Iran (Mahboubi and Aramesh, 1980; Islami et al., 2009). Results of a study showed that drinking hot or very hot tea increased the risk of oesophageal cancer by 2.07 and 8.16 times among Iranian population, respectively (Islami et al., 2007). Currently, Iran is one of the known areas with a high incidence of esophageal cancer in the world (Mosavi-Jarrahi and Mohagheghi, 2006). Further attempts such as developing educational campaigns to inform the population about the hazards of drinking hot tea is needed in the high-risk population (Dong et al., 2002; Islami et al., 2007). In this regard, campaigns are a series of goal-oriented efforts to inform, persuade or motivate behavior change of a specific audience through an organized set of communication activities that take place in a defined time period (The Health Communication Unit of the Center for Health Promotion of Toronto University, 2009). It is important to note that behavioral change theories can help identify the beliefs that should be targeted in a campaign (Fishbein and Cappella, 2006). Using the theories may increase the effectiveness of cancer awareness campaigns (Papas et al., 2004). In this study, we used Theory of Planned Behavior (TPB) as a theoretical framework for designing an educational campaign. TPB is one of the behavioral theories which has been widely applied to predict preventive behaviour of various cancers (Jennings-Dozier, 1999; Godin et al., 2001). TPB assumes that behavioural intention is the most determinant of behaviour, which is in turn determined by attitude to performing the behaviour (or the overall evaluations

${ }^{1}$ Department of Health Education and Health Promotion, School of Health, Iran University of Medical Sciences, Tehran, ${ }^{2}$ Department of Biostatistics and Epidemiology, School of Health, Jundishapur University of Medical Sciences, Ahvaz, Iran *For correspondence: dehdarit@yahoo.com 
of the behaviour by the individual), subjective norms associated with the behaviour (or individual's beliefs about whether significant others think he/she should engage in the recommended behaviour) and perceived behavioural control over the behaviour (or individual's beliefs of the extent to which performance of the target behaviour is easy or difficult) (Conner and Norman, 2005; Glanz et al., 2008). To the best of the authors' knowledge, no intervention has been implemented for reducing hot tea consumption in the world and also in Iran. Previous studies generally focus on determining the association between high-temperature beverage drinking habits and the risk of esophasial cancer (Jenkins et al., 1999; Boonyaphiphata et al., 2002; Islami et al., 2009). Therefore, given the advantages of educational campaigns in the prevention of cancer (Jenkins et al., 1999; Smit-Kroner and Brumby, 2015) and also the importance of changing unhealthy eating habits (e.g. drinking hot tea) from an early age, present study was undertaken to examine the effect of an educational campaign based on TPB items on reducing hot tea consumption among a sample of Iranian female students.

\section{Materials and Methods}

\section{Study participants and setting}

The study was carried out among 130 primary-school female students in Salas Babajani, Kermanshah, Iran, during October 2014-March 2015. Given the sample size, two primary schools were randomly selected. Then, sixty five students were randomly selected from each school and assigned to either the intervention group or the control group. Inclusion criteria in the study were: the student's agreement to participate, ability to read and write Persian, residency in Salas Babajani and studying in the $5^{\text {th }}$ and $6^{\text {th }}$ grade. The protocol of the study was approved by the Ethics Committee of Iran University of Medical Sciences. All students were informed about the objectives of the study and a written consent was obtained from each of them.

\section{Study instruments and measures}

Demographic characteristics, hot tea consumption, and TPB variables were measured by a self-administered questionnaire which was elaborated and developed by the study researchers. It should be noted that TPB variables were assessed directly. To develop the hot tea consumption and TPB variables, we surveyed the literature and interviewed eighteen female students to collect their opinions concerning the intake of hot tea. Then, the twenty female students were asked to comment on the simplicity, clarity, and readability of the items. According to their comments, some unclear questions and wording errors were modified. About five questions were rewritten or deleted in this stage. Content validity of the instrument items was assessed quantitatively. For this aim, the content validity ratio (CVR) and content validity index (CVI) of each item were calculated based on the opinions of an expert panel of ten specialists in health education and nutrition regarding the necessity and relevance of the items. According to the Lawshe Table, an acceptable CVR for a ten-expert panel is 0.62 (Lawshe, 1975). So, items having CVR less than 0.62 were deleted. Polit and Beck (Polit and Beck, 2004) suggested 0.80 as the acceptable lower limit for the CVI. Therefore, items having CVI less than 0.80 were omitted from the instrument. After calculating CVI and CVR, a total of three items (2 items in the perceived behavioral control sub-scale and 1 item in the subjective norms sub-scale) were deleted from the scale. To estimate the reliability of the hot tea consumption item, a test-retest correlation coefficient procedure was used with twenty four female students (with a 2-week interval between each test). The satisfactory value for the correlation coefficient was considered $\geq 0.67$ (Landis and Koch, 1997). In addition, Cronbach's $\alpha$ was used to estimate the internal consistency of the items in the subscales. The estimate of $\alpha \geq 0.70$ is considered satisfactory. (Cronbach, 1951).

\section{Attitude towards hot tea consumption}

Four items were used to measure attitude regarding hot tea consumption (e.g. 'I think that drinking hot tea is an unhealthy behavior'). The items in this sub-scale were measured on a Likert-type scale, ranging from 1= "Strongly disagree" to 7 = "Strongly agree". Cronbach's $\alpha$ for the competing demands scale was 0.85 .

\section{Subjective norms for hot tea consumption}

Three items were used to measure the subjective norms (e.g. 'most people who are important to me think that I should drink no hot tea'). The items in this sub-scale were measured on a Likert-type scale ranging from 1 = "never" to 4 = "always". Cronbach's $\alpha$ for the competing demands scale was 0.82

\section{Perceived behavioral control for drinking no hot tea}

Seven items were used to measure perceived behavioral control (e.g. 'Even if all my family members drink hot tea, I can consume no hot tea'). The items of this sub-scale were measured on a Likert-type scale ranging from $1=$ 'completely unconfident' to $5=$ 'completely confident'. Cronbach's $\alpha$ estimated for this sub-scale was 0.77 .

\section{Intention to drink no hot tea}

Three items were used to measure the student's intention to drink no hot tea (e.g. 'I plan to drink no hot tea). The items in this scale were measured on a Likerttype scale, ranging from 1 = "Strongly disagree" to $5=$ "Strongly agree". Cronbach's $\alpha$ of this sub-scale was 0.95 .

\section{Hot tea consumption}

One item was used to measure the hot tea intake (Do you drink hot tea?). This item was measured on a Likerttype scale ranging from $1=$ 'never' to $5=$ 'always'. The test-retest correlation coefficient for this sub-scale was $0.81(\mathrm{P}$-value $=0.001)$.

\section{The campaign program for reducing hot tea consumption}

The campaign program was implemented within eight weeks for the intervention participants. In fact, campaigns are the most effective when they include a combination of media, interpersonal and community events for dissemination of information (The Health Communication 
Prevention of Esophageal Cancer: Experience of an Educational Campaign for Reducing Hot Tea Consumption in Iran

Unit of the Center for Health Promotion of Toronto University, 2009). We used various communication channels such as posters and pamphlets along with small group and individual activities for delivering information to the students. The name of the campaign ('tea is good, but not hot') and its logo was selected through conducting a brain storming with the students in the intervention group. Also, a total of one session for their parents and teachers and three 45-minute training sessions for the students were conducted during the campaign period. In the first session, the disadvantages of hot tea consumption were explained for the parents and teachers. In this meeting, they were encouraged to persuade students to drink no hot tea. In the second session, after presenting an educational clipart which presented explicit illustrations and movies about esophageal cancer and its risk factors, the prevalence of esophageal cancer in Iran, the important role of hot tea consumption in this cancer and other disadvantages of drinking hot tea were explained for the students. At the end of this session, an instructional pamphlet on the issue was given to the participants. It should be noted that during the sessions, the students were divided into small groups and through lectures, focus group discussions, question and answer and role-playing received appropriate instructions for reducing eating hot tea. In the third session, the

Table 1. Descriptive statistics of participant characteristics in the two groups $(n=130)$

\begin{tabular}{lrrrr}
\hline & $\begin{array}{c}\text { Intervention } \\
\text { group }\end{array}$ & \multicolumn{2}{c}{$\begin{array}{c}\text { Control } \\
\text { group }\end{array}$} \\
\cline { 2 - 5 } & $\mathrm{n}$ & $\%$ & $\mathrm{n}$ & $\%$ \\
\hline Occupation of father & & & & \\
$\quad$ Self-employed & 0 & 41.5 & 30 & 46.2 \\
Employee & 0 & 10 & 15.4 \\
$\quad$ Casual labourer & 3 & 27.7 & 22 & 33.8 \\
$\quad$ Retired & & & 0 & 0 \\
Occupation of mother & 1 & 1.5 & 2 & 3.1 \\
$\quad$ Self-employed & 1 & 1.5 & 0 & 0 \\
Employee & 59 & 90.8 & 61 & 93.8 \\
$\quad$ Household duties & & & & \\
Father's education level & 7 & 10.8 & 11 & 16.9 \\
$\quad$ illiterate & 51 & 78.6 & 41 & 63 \\
$\quad$ 12th grade & 6 & 9.4 & 7 & 10.8 \\
$\quad>12$ th grade & & & & \\
Mother's education level & 11 & 16.9 & 16 & 24.6 \\
$\quad$ illiterate & 51 & 78.5 & 49 & 75.3 \\
$\quad \leq 12$ th grade & 2 & 3.1 & 0 & 0 \\
$\quad$ 12th grade & & & & \\
History of esophageal cancer in family & & 4.6 & 1 & 1.5 \\
$\quad$ Yes & 3 & & & \\
\hline
\end{tabular}

students were encouraged to discuss about the positive and negative attitudes and insights in terms of hot tea consumption. They were also instructed to drink no hot tea and also encourage others to no consume it. In addition, they were requested to eat no hot tea and record their experiences on a form and keep the form with them for use in the future session. In the fourth session, by posing some open-ended questions, the students were asked to share their experiences and feelings with other participants upon hot tea consumption. It is worth mentioning that the majority of reported positive experiences by the students about hot tea consumption (such as reducing fatigue, anxiety and relaxation feeling) were mainly associated with the caffeine in tea and not its hotness. In this session, false beliefs about the benefits of drinking hot tea were dissuaded and through verbal persuasions, the students were assured that they could drink no hot tea. In addition, through a role-playing, ways of reducing the temperature of tea such as using saucer or wide span cups or glasses, adding relatively cold water to hot tea, blink of hot tea with a teaspoon and waiting to reduce the temperature of it were instructed to the participants. During the 8-week period of the campaign, several posters developed by the researchers in the present study about the disadvantages of hot tea consumption and the ways of reducing its temperature were hanged inside the school.

\section{Data analysis}

The data were analyzed by SPSS software package (version 17.0, SPSS, Inc., Chicago, IL, USA). The homogeneity of demographic variables, hot tea consumption and TPB variables of the two groups were analyzed by independent-samples t- tests and Chi-square. Data normality was tested using Kolmogorov-Smirnov test. The differences in the total mean scores of TPB variables before and after the campaign in each group were tested by means of Student's paired-samples t-test. The differences in the total mean scores of TPB variables between the groups after the campaign were tested by Analysis of Covariance (ANCOVA). Mann-Whitney U test was used to identify significant differences in hot tea consumption between the groups. Also, Wilcoxon test was used to identify significant differences in hot tea consumption before and after the campaign in each group. The correlation of hot tea consumption with each of TPB variable was determined by Spearman correlation coefficient. The data were reported as mean \pm SD. $\mathrm{P}<0.05$ was considered significant.

Table 2. Correlation of hot tea consumption with attitude, perceived behavioral control, subjective norms and behavioral intention in the two groups before and after the intervention $(n=130)$

\begin{tabular}{|c|c|c|c|c|}
\hline & \multicolumn{2}{|c|}{ Intervention group } & \multicolumn{2}{|c|}{ Control group } \\
\hline & Before intervention & After intervention & Before intervention & After intervention \\
\hline Attitude & 0.11 & $0.33 *$ & 0.09 & $0.31 *$ \\
\hline Perceived behavioral control & -0.14 & -0.02 & $-0.01 *$ & -0.05 \\
\hline Subjective norms & 0.06 & $-0.33 *$ & 0.05 & -0.21 \\
\hline Behavioral intention & -0.03 & -0.03 & -0.19 & -0.23 \\
\hline
\end{tabular}

*Correlation was significant: $* \mathrm{P}<0.05$ 
Table 3. Comparison of mean scores of attitude, perceived behavioral control, subjective norms, behavioral intention and hot tea consumption in the two groups before and after the intervention $(n=130)$

\begin{tabular}{|c|c|c|c|c|c|c|c|c|}
\hline & \multicolumn{4}{|c|}{ Intervention group } & \multicolumn{4}{|c|}{ Control group } \\
\hline & \multicolumn{2}{|c|}{ Before intervention } & \multicolumn{2}{|c|}{ After intervention } & \multicolumn{2}{|c|}{ Before intervention } & \multicolumn{2}{|c|}{ After intervention } \\
\hline & Mean & SD & Mean & $\mathrm{SD}$ & Mean & $\mathrm{SD}$ & Mean & $\mathrm{SD}$ \\
\hline Attitude & 16.46 & 2.64 & $7.00 *+$ & 4.22 & 15.64 & 2.30 & $12.03 *$ & 5.50 \\
\hline Perceived behavioral control & 23.8 & 5.07 & $30.23^{* \dagger}$ & 7.82 & 25.07 & 4.98 & 25.3 & 4.64 \\
\hline Subjective norms & 8.61 & 3.63 & $9.55 \dagger$ & 3.08 & 8.87 & 3.08 & 8.58 & 3.03 \\
\hline Behavioral intention & 9.90 & 2.88 & $12.29 * \dagger$ & 2.65 & 10.7 & 3.17 & 10.6 & 3.49 \\
\hline Hot tea consumption & 2.54 & 1.03 & $1.80 \beta \alpha$ & 0.93 & 2.35 & 1.36 & 2.35 & 1.36 \\
\hline
\end{tabular}

*Mean values were significantly different from those of the control group (analysis of covariance): $\dagger \mathrm{P}<0.05$; Mean values were significantly different from those before the campaign (paired-samples t test): $* \mathrm{P}<0.05$; Mean values were significantly different from those of the control group (MannWhitney $\mathrm{U}$ test): $\alpha \mathrm{P}<0.05$; Mean values were significantly different from those before the campaign (Wilcoxon test): $\beta \mathrm{P}<0.05$.

\section{Results}

Table 1 shows the demographic characteristics of the students in both groups. No significant differences were found between the two groups for any of the demographic characteristics at baseline. It is worth mentioning that all $(100 \%)$ of the participants regularly drank black tea every day. Results indicated that there were significant differences in drinking no hot tea and TPB variables (except for subjective norms) in the intervention group as compared to the control group after the campaign (see Table 3). Correlation analysis of the hot tea consumption with TPB variables is shown in Table 2.

\section{Discussion}

Results of the present study showed that considerable increase occurred in drinking no hot tea in the intervention group compared with the control group after the campaign. So that, the number of no hot tea consumers increased to about 2 times (from $13.7 \%$ to $25.38 \%$ ) after the campaign. This finding is consistent with similar studies regarding the role of campaign in increasing cancer screening and reducing health-risk behaviours (Jenkins et al., 1999; Jongudomkarn, 2014; Smit-Kroner and Brumby, 2015). In the same line, Rodui and Cold reported that conducting anti-smoking campaigns decrease smoking, as an important risk factor for lung cancer, among younger smokers (Rodu and Cole, 2002). Ismail et al. demonstrated that campaigns can promote screening of oral cancer (Ismail et al., 2012). In summary, the results highlighted the need for conducting further educational campaigns that will influence other modifiable risk factors of esophasial cancer (e.g. low consumption of fruits and vegetable) among Iranian population.

Our finding showed that the intervention group had not more subjective norms for drinking no hot tea compared to the control group after the implemented campaign. The subjective norms are an individual's perception of social pressures to perform or not perform the specific behaviour (Glanz et al., 2008). In some studies, researchers have reported that this variable was one of the significant predictors of cancer preventive practices (Hennig and Knowles, 1990; Katapodi et al., 2005; Gili et al., 2006). For example, Hennig and Knowles demonstrated that doctors were a significant reference in women decision to have a Pap test (Hennig and Knowles, 1990). Vries et al. reported that receiving support from parents and friends can increase the use of sun-protective practices among the adolescents (Vries et al., 2005). It is suggested that influencing individuals on target audience behaviors was identified and also involved in the intervention programs. Also, measuring other social determinants such as social capital is recommended (Rimaz et al., 2014).

The results of this study showed that the intervention group had more perceived behavioral control to drinking no hot tea when compared to the control group after the campaign, which was consistent with the findings of Dehdari et al. (2014). Also, Branstrom et al. (2004) reported that perceived behavioral control had direct association with preventive skin cancer practices (Branstrom et al., 2004). Furthermore, in the current study, there was an inverse correlation between drinking hot tea and perceived behavioral control in the two groups before and after the campaign (see Table 2). In other words, students with a high level of perceived behavioural control were less likely to drink hot tea. Given the importance of perceived behavioural control to adopt cancer preventive behaviour (Vries et al., 2005), it seems necessary that educational campaigns be designed, taking into account the various sources of information (including mastery experiences, physiological state, verbal persuasion and vicarious experiences) which influence the individuals' ability to perform the specific behaviour (Bandura et al., 1977). For this aim, when designing more effective campaigns, using various communication channels such as mass media accompanied with developing small group and other individual activities is recommended (The Health Communication Unit of the Center for Health Promotion of Toronto University, 2009). These various communication channels may enhance students' selfefficacy for drinking no hot tea. Finally, we propose that more efforts are needed to identify the best methods of manipulating individuals " perceived behavioural control within an educational campaign.

Following the campaign, there was a significant reduction in the positive attitude toward drinking hot tea in the intervention group than the control group which is consistent with the findings of similar studies (Hingle et al., 2014; Jongudomkarn, 2014; Kye et al., 2015). Kye et 
al. reported that television advertisements may improve the citizen's knowledge and beliefs regarding cancer prevention (Kye et al., 2015). In a study, Smith et al. showed that mass media campaign can promote children's attitude to performing sun- protective practices (Smith et al., 2002). Developing appropriate interventions for sustainable changes in cancer-related attitudes and beliefs depends on using appropriate persuasion strategies. For this purpose, applying theories of persuasion, such as the elaboration likelihood model and protection motivation theory in the planning of communication campaigns to change health behaviors has been suggested (Slater, 1999).

In this study, we found that the mean score on behavioral intention for drinking no hot tea increased significantly in the intervention group compared with the control group following the campaign. This finding is consistent with Dehdari et al. They demonstrated that education intervention may increase women's intention to have the Pap test (Dehdari et al., 2014). Therefore, as developing appropriate strategies for increasing behavioral intention depends on exactly understanding its determinants; further studies on this issue is suggested. In such previous studies, predictors of intention to preventing cancer were reported. For example, McCaffery et al. showed that the level of knowledge and negative attitude about cancer may impact on individuals, intention for participating in colorectal cancer screening programs (McCaffery et al., 2003). Dong-Ling Wang et al. also found that cancer-related worry/anxiety and social influences were two important predictors of females' intention to undergo vaccination against Human Papillomavirus (Dong-Ling Wang et al., 2015). Roncancio et al. reported that subjective norms and perceived behavioral control had direct association with the intention of females to be screened for cervical cancer (Roncancio et al., 2015). Rooshanpour Dehbari et al. demonstrated that perceived rewards, response efficacy, fear, self-efficacy and marital status were the five variables which could predict $39 \%$ variance of college students intention to perform sun-protective practices (Rooshanpour Dehbari et al., 2015). More researches in this area are needed in Iran.

Although this study highlights the effect of a campaign based on TPB variables for reducing hot tea consumption among a sample of Iranian female students, it had some limitations, too. As the first limitation the samples were selected from primary-school female students in Salas Babajani, Kermanshah, Iran. Therefore, the findings cannot be generalized to other groups (e.g. male students). As the second major limitation of the present study the short duration of the follow-up sessions can be counted. Investment on longer campaigns to achieve larger population exposure to media messages is perposed.

Conclusion

The results of the study showed that conducting educational campaigns based on TPB could decrease drinking of hot tea among Iranian female students.

\section{Acknowledgements}

The study was supported by Iran University of Medical Sciences, grant number 25807. The authors would like to thank female students who participated in this study.

\section{References}

Bandura A, Adams NE, Beyer J (1977). Cognitive processes mediating behavioral change. J Pers Soc Psychol, 35, 125-39.

Boonyaphiphat $\mathrm{P}$, Thongsuksai $\mathrm{P}$, Sriplung H, et al (2002). Lifestyle habits and genetic susceptibility and the risk of esophageal cancer in the Thai population. Cancer lett, 186, 193-9.

Branstrom R, Ullen H, Brandberg Y (2004). Attitudes, subjective norms and perception of behavioural control as predictors of sun-related behaviour in Swedish adults. Prev Med, 39, 992-9.

Cho H, Salmon CT (2007). Unintended effects of health communication campaigns. J Commun, 57, 293-317.

ConnerM, Norman P. Predicting health behaviour. Second edition; McGraw-Hill: Open University Press, 2005.

De Vries H, Lezwijn J, Hol M, et al (2005). Skin cancer prevention: behaviour and motives of Dutch adolescents. Eur J Cancer Prev, 14, 39-50.

Cronbach L (1951) Coefficient alpha and the internal structure of tests. Psychometrika, 16, 297-334.

Dehdari T, Hassani L, Hajizadeh E, et al (2014). Effects of an educational intervention based on the protection motivation theory and implementation intentions on first and second pap test practice in Iran. Asian Pac J Cancer Prev, 15, 7257-61.

Dong Z, Tang P, Li L, et al (2002). The strategy for esophageal cancer control in high-risk areas of China. Jpn J Clin Oncol, 32, $10-2$.

Fishbein M, Cappella JN (2006). The role of theory in developing effective health communications. J Commun, 56, 1-17.

Gardner E, Ruxton C, Leeds A (2007). Black tea-helpful or harmful? A review of the evidence. Eur J Clin Nutr, 61, 3-18.

Gili M, Roca M, Ferrer V, et al (2006). Psychosocial factors associated with the adherence to a colorectal cancer screening program. Cancer Detect Prev, 30, 354-60.

Glanz K, Rimer B, Viswanath k. Health behavior and health education: theory, research and practice. $4^{\text {th }}$ ed. San Francisco: Jossey- Bass, 2008.

Godin G, Gagné C, Maziade J, et al (2001). Breast cancer: the intention to have a mammography and a clinical breast examination-application of the theory of planned behavior. Psychol Health, 16, 423-41.

Hennig P, Knowles A (1990). Factors influencing women over 40 years to take precautions against cervical cancer. $J$ Appl Soc Psychol, 20, 1612-21.

Hingle MD, Snyder AL, McKenzie NE, et al (2014). Effects of a short messaging service-based skin cancer prevention campaign in Adolescents. Am J Prev Med, 47, 617-23.

Islami F, Boffetta P, Ren JS, et al (2009). High-temperature beverages and foods and esophageal cancer risk-A systematic review. Int J Cancer, 125, 491-524.

Islami F, Pourshams A, Nasrollahzadeh D, et al (2009). Tea drinking habits and oesophageal cancer in a high risk area in northern Iran: population based case-control study. $B M J$, 338, 929.

Ismail AI, Jedele JM, Lim S, et al (2012). A marketing campaign to promote screening for oral cancer. J Am Dent Assoc, $143,57-66$

Jenkins CN, McPhee SJ, Bird JA, et al (1999). Effect of a media-led education campaign on breast and cervical cancer screening among Vietnamese-American women. Prev Med, 28, 395-406.

Jennings-Dozier K (1999). Predicting intentions to obtain a Pap smear among African American and Latina women: Testing 
the theory of planned behavior. Nurs Res, 48, 198-205.

Jongudomkarn D (2014). A volunteer alcohol consumption reduction campaign: participatory action research among Thai women in the Isaan region. Asian Pac J Cancer Prev, 15, 7343-50.

Katapodi MC, Facione NC, Miaskowski C, et al (2002). The influence of social support on breast cancer screening in a multicultural community sample. Oncol Nurs Forum, 29, 845-52.

Kye SY, Yoo J, Lee MH, et al (2014). Effects of a cancer prevention advertisement on beliefs and knowledge about cancer prevention. Asian Pac J Cancer Prev, 16, 5793-800.

Landis JR, Koch GG (1997). The measurement of observer agreement for categorical data. Biometrics, 33, 159-74.

Lawshe CH (1975). A quantitative approach to content validity. Pers Psychol, 28, 563-75.

Mahboubi EO, Aramesh B (1980). Epidemiology of esophageal cancer in Iran, with special reference to nutritional and cultural aspects. Prev Med, 9, 613-21.

McCaffery K, Wardle J, Waller J (2003). Knowledge, attitudes, and behavioral intentions in relation to the early detection of colorectal cancer in the United Kingdom. Prev Med, 36, 525-35.

Mosavi-Jarrahi A, Mohagheghi MA (2006). Epidemiology of esophageal cancer in the high-risk population of Iran. Asian Pac J Cancer Prev, 7, 375-80.

Onuk MD, Oztopuz A, Memik F (2001). Risk factors for esophageal cancer in eastern Anatolia. Hepato-Gastroenterol, 49, 1290-2.

Papas RK, Logan HL, Tomar SL (2004). Effectiveness of a community-based oral cancer awareness campaign (United States). Cancer Cause Control, 15, 121-31.

Polit DF, Beck CT (2004). Nursing Research: Principles and Methods, $46^{\text {th }}$ ed., 416-45. Philadelphia, PA: Lippincott.

Rimaz SH, Mohammad K, Dastoorpoor M, et al (2014). Investigation of relationship between social capital and quality of life in multiple sclerosis patients. Glob J Health Sci, 6, 261-72.

Rodu B, Cole P (2002). Impact of the American anti-smoking campaign on lung cancer mortality. Int J Cancer, 97, 804-6.

Roncancio AM, Ward KK, Sanchez IA, et al (2015). Using the theory of planned behavior to understand cervical cancer screening among Latinas. Health Educ Behav, 42, 621-6.

Rooshanpour Dehbari S, Dehdari T, Dehdari L, et al (2015). Predictors of sun-protective practices among Iranian female college students: application of protection motivation theory. Asian Pac J Cancer Prev, 16, 6477-6480.

Salahinejad M, Aflaki F (2010). Toxic and essential mineral elements content of black tea leaves and their tea infusions consumed in Iran. Biol Trace Elem Res, 134, 109-17.

Slater MD (1999). Integrating application of media effects, persuasion, and behavior change theories to communication campaigns: a stages-of-change framework. Health Commun, 11,335-54.

Smit-Kroner C, Brumby S (2015). Farmers sun exposure, skin protection and public health campaigns: an Australian perspective. Prev Med Rep, 2, 602-7.

Smith BJ, Ferguson C, McKenzie J, et al (2002). Impacts from repeated mass media campaigns to promote sun protection in Australia. Health Promot Int, 17, 51-60.

The Health Communication Unit of the Center for Health Promotion of Toronto University, (2009). Overview of Health Communication Campaigns.

Wang LD, Lam WW, Wu J, Fielding R (2015). Psychosocial determinants of Chinese parental HPV vaccination intention for adolescent girls: preventing cervical cancer. Psycho Oncol. (In press)
Yuan JM, Sun C, Butler LM (2011). Tea and cancer prevention: epidemiological studies. Pharmacol Res, 64, 123-35. 